\title{
Segregation in squeeze casting 6061 aluminum alloy wheel spokes and its formation mechanism
}

\author{
Fan-bo Meng', *Hong-jun Huang', Xiao-guang Yuan', Xue-jian Lin', Ze-wen Cui', Xian-lei $\mathrm{Hu}^{3}$ \\ 1. School of Materials Science and Engineering, Shenyang University of Technology, Shenyang 110870, China \\ 2. School of Materials Science and Engineering, Liaoning Technology University, Fuxin 123000, China \\ 3. State Key Laboratory of Rolling and Automation, Northeastern University, Shenyang 110004, China
}

\begin{abstract}
Segregation can seriously damage the mechanical properties of the aluminum alloys. 6061 aluminum alloy wheel spokes were prepared by squeeze casting. To investigate the formation mechanism of segregation, the microstructure of the alloy was observed using scanning electron microscopy, energy dispersive spectrometry, $\mathrm{X}$-ray diffraction and electron microprobe analysis methods. The Gibbs energy of each phase during solidification was calculated by JMatPro. Results show that the segregation phases in the R-joint of the wheel spokes are mainly composed of $\mathrm{Mg}_{2} \mathrm{Si}, \beta-\mathrm{AlFeSi}$ and $\mathrm{Al}_{5} \mathrm{Cu}_{2} \mathrm{Mg}_{8} \mathrm{Si}_{6}$ intermetallics. During the solidification of the 6061 aluminum alloy wheels, $\mathrm{Mg}_{2} \mathrm{Si}$ and $\alpha-\mathrm{AlFeSi}$ phases precipitate in the mushy zone at first. With the decrease of temperature, $\alpha$-AlFeSi transforms into $\beta$-AIFeSi, while $\mathrm{Al}_{5} \mathrm{Cu}_{2} \mathrm{Mg}_{8} \mathrm{Si}_{6}$ precipitates from the solid-state aluminum alloy after solidification. Segregation at the R-joint of wheel spokes is mainly caused by insufficient cooling, so the cooling during alloy solidification should be enhanced to avoid segregation.
\end{abstract}

Key words: 6061 aluminum wheels; segregation; squeeze casting; $\mathrm{Mg}_{2} \mathrm{Si} ; \mathrm{AlFeSi} ; \mathrm{Al}_{5} \mathrm{Cu}_{2} \mathrm{Mg}_{8} \mathrm{Si}_{6}$

CLC numbers: TG146.21 Document code: A Article ID: 1672-6421(2021)01-045-07

\section{Introduction}

The 6061 aluminum alloy (Al-Mg-Si) is a mediumstrength wrought alloy, widely used in aviation, automobiles and other fields due to its high formability and corrosion resistance ${ }^{[1-3]}$. Recently, the 6061 aluminum alloy has been used to manufacture wheels, which are mainly made by forging due to the low flow capacity of the alloy ${ }^{[4]}$. Squeeze casting is a new metal forming method in which pressure is applied to the metals in the mushy zone, so the forming process is simple and could make high-performance products ${ }^{[5]}$. Yin et al. ${ }^{[6]}$ fabricated an aluminum alloy connecting rod of an air compressor by squeeze casting, which eliminated defects such as pores and non-metallic inclusions which often occur in the parts by die casting, reduced the investment for forging equipment, and improved the utilization rate and productivity of materials. Stangeland et al. ${ }^{[7]}$ prepared 6061 aluminum alloy wheels by squeeze casting, but segregation was found at the R-joint of wheel spokes. The segregation of 6061 aluminum alloy

*Hong-jun Huang

Male, Ph. D., Professor. His research mainly focused on composition design and forming technologies of aluminum and titanium alloys.

E-mail: huanghong1977@163.com;

Received: 2020-06-03; Accepted: 2020-10-22 is related to the cooling rate during solidification, and the slower the cooling rate, the easier the segregation occurs ${ }^{[8]}$. Seo et al. ${ }^{[8]}$ calculated the microsegregation of 6061 alloy with the Scheil equation and ascribed the segregation of the alloy to the transformation of intermetallic compounds containing $\mathrm{Mg}_{2} \mathrm{Si}$ and $\mathrm{Fe}$. It was found that the degree of segregation in the 6061 alloy was dependent on the growth rate under given solidification conditions. Wang et al. ${ }^{[9]}$ found that the segregation in 6061 aluminum alloy was mainly caused by the $(\mathrm{FeMn})_{3} \mathrm{Si}_{2} \mathrm{Al}_{15}$ phase. Magnus et al. ${ }^{[10]}$ believed that the segregation in Al-Mg-Si alloy was mainly due to the formation of coarse Si-particles and $\mathrm{Mg}_{2} \mathrm{Si}$ particles during solution heat treatment. Basak et al. ${ }^{[1]}$ found the $\beta$ phase composed of $\mathrm{Si}$ and $\mathrm{Fe}$ in Al-Si alloy is the main cause of segregation. It was also found that the morphological change of beta-phase and Si could help in recovering the strength and ductility in the recycled Al-Si alloys. In summary, although many studies have investigated the segregation in 6061 aluminum alloy, few of them focused on the type and mechanism of segregation in detail.

Segregation in alloy will seriously damage the mechanical properties of the alloy, so this study focuses on the segregation and its formation mechanism in squeeze casting of 6061 aluminum alloy wheels. The microstructure of the alloy was observed using 
scanning electron microscopy, energy dispersive spectrometry, $\mathrm{X}$-ray diffraction and electron microprobe analysis methods. The preventive measure to segregation was proposed.

\section{Experimental method}

Commercial 6061 aluminum alloy was melted at $750{ }^{\circ} \mathrm{C}$ in a resistance furnace. The chemical compositions of the alloy are listed in Table 1. Metal molds were used, as shown in Fig. 1, which were preheated at $300{ }^{\circ} \mathrm{C}$ for the lower mold and $170{ }^{\circ} \mathrm{C}$ for the upper mold. Then, the molten alloy was poured at $720^{\circ} \mathrm{C}$ to the lower metal mold. When the melt temperature in the lower mold decreased to $670{ }^{\circ} \mathrm{C}, 3,000 \mathrm{t}$ pressure was applied to the upper mold and held for $20 \mathrm{~s}$, then the upper and lower molds were closed. Finally, the upper mold was removed, and the wheel was taken out. During the squeeze casting, the molds were cooled with cooling water.

The samples for microstructure observation were cut from the segregation zone of the wheel. After grinding and

Table 1: Chemical composition of 6061 aluminum alloy (wt.\%)

\begin{tabular}{ccccccccc}
$\mathrm{Mg}$ & $\mathrm{Si}$ & $\mathrm{Cu}$ & $\mathrm{Fe}$ & $\mathrm{Mn}$ & $\mathrm{Cr}$ & $\mathrm{Ti}$ & $\mathrm{Zn}$ & $\mathrm{Al}$ \\
\hline 1.04 & 0.74 & 0.20 & 0.18 & 0.05 & 0.06 & 0.10 & 0.004 & Bal.
\end{tabular}

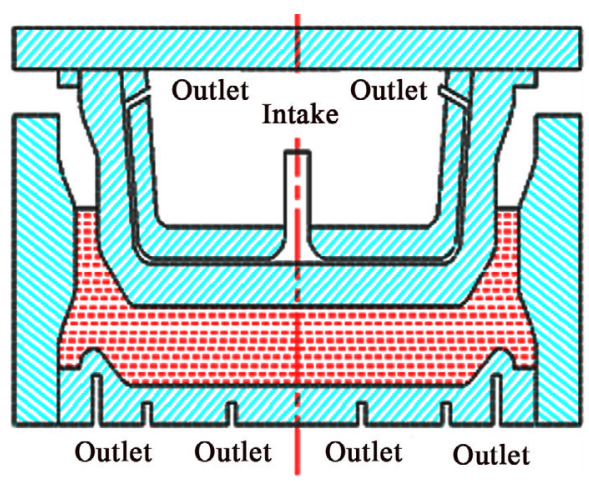

Fig. 1: Dies for squeeze casting of aluminum wheel polishing, the samples were corroded with $0.5 \%$ HF acid for $15 \mathrm{~s}$. The microstructure of alloy was observed using Axio Vert.A1 optical microscopy and scanning electron microscopy (JSM-7100F SEM), the phase constitution was characterized by X-ray diffraction (Shimadzu 7000 XRD), and the distribution of elements was characterized by electron microprobe analysis (Shimadzu EMPA-1720).

\section{Results and discussion}

Figure 2 shows the macro-morphology of segregation (circle area) and its location in the 6061 aluminum alloy wheel prepared by squeeze casting.

Segregation occurs at the R-joint of wheel spokes, and the segregation zones are distributed in the samples with a long strip shape (Fig. 2).

Figure 3 shows the microstructures of the alloy at the wheel spoke. It can be seen from Fig. 3(a) that a small amount of granular precipitates distributed in the grain and at the grain boundary of the 6061 aluminum alloy wheel spokes in the zone without segregation. However, a large amount of fishbone, bulky and strip-like second phases appear in the segregation zone.

Figure 4 shows the XRD results of the zones with and without segregation. It can be seen clearly that there are mainly $\alpha-\mathrm{Al}$ and $\mathrm{Mg}_{2} \mathrm{Si}$ in the zone without segregation, and $\mathrm{AlFeSi}$ phases appear in the segregated zone in addition to $\alpha$-Al and $\mathrm{Mg}_{2} \mathrm{Si}$ (Fig. 4).

Figure 5 shows the microstructure of the segregation zone. Clearly, the morphology, size and distribution of segregation are different. The white phases are massive and long strip, the black phases are fishbone-like and in small pieces, and some light gray rod-like second phases appear in Region 6, and some black bulky phases are found near the rod-like phases.

Energy dispersive spectrometry (EDS) was carried out on different points as indicated in Fig. 5, and the results are shown in Table 2 . (a)

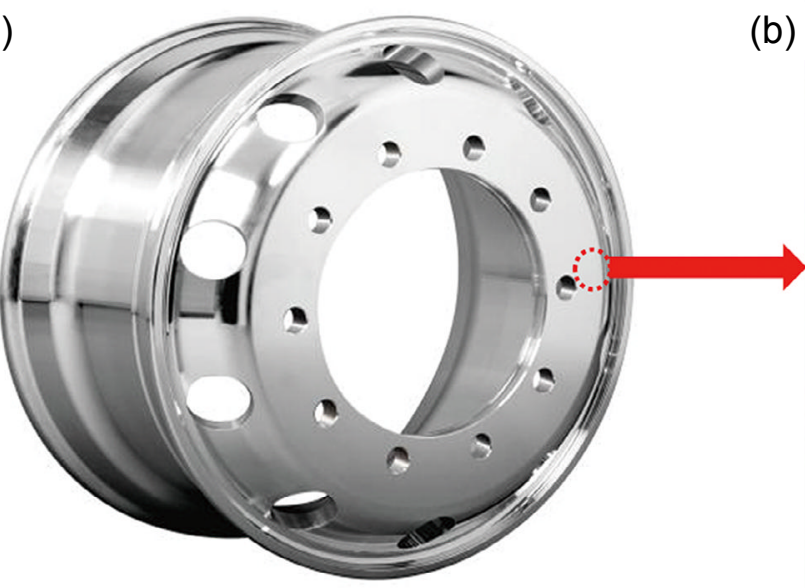

(b)

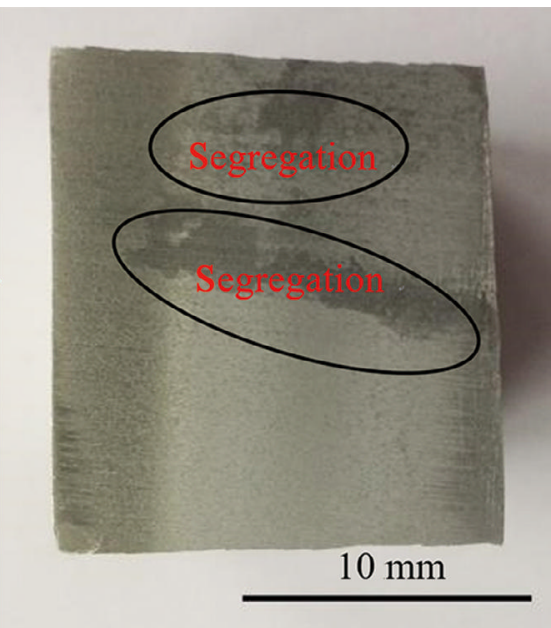

Fig. 2: 6061 aluminum alloy wheel (a) and segregation zone (b) 


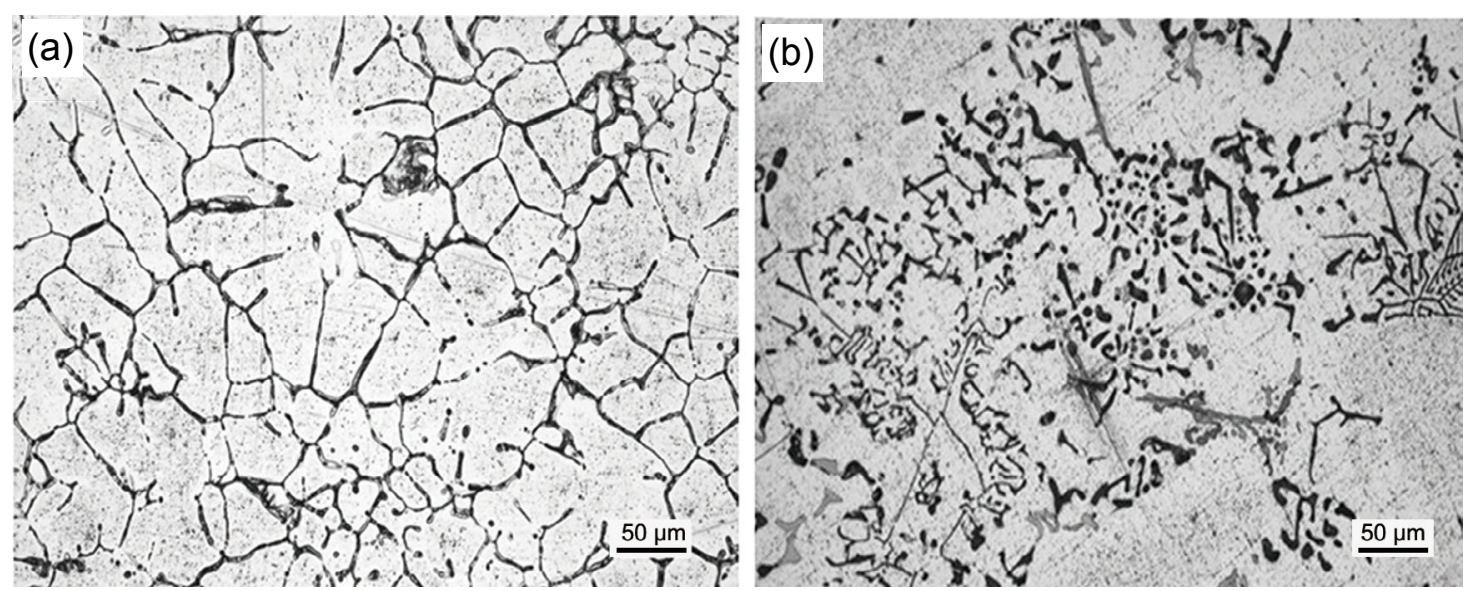

Fig. 3: Microstructure of 6061 aluminum alloy wheel spoke at zones without (a) and with (b) segregation

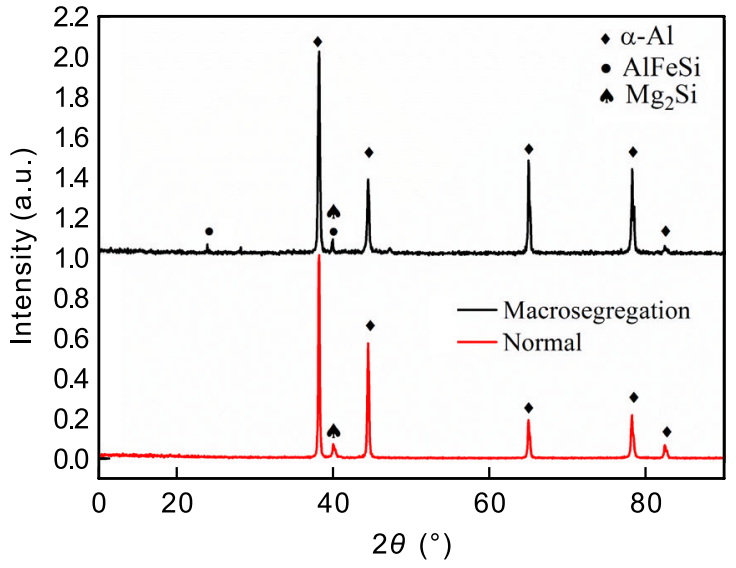

Fig. 4: XRD patterns of 6061 aluminum alloy
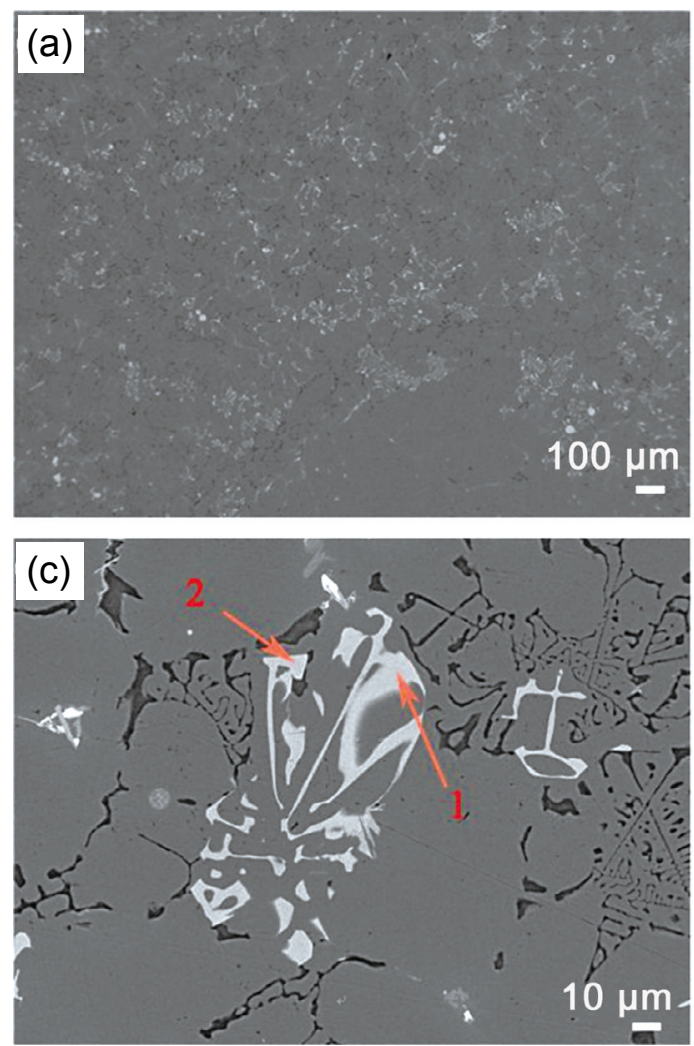

EDS results in Table 2 show that the white blocks (Points 1 and 2) in Fig. 5 mainly contain $\mathrm{Si}$ and $\mathrm{Fe}$, the black fishbone and blocky precipitates (Points 3 and 4) mainly consist of $\mathrm{Mg}$ and $\mathrm{Si}$, and the light gray blocks (Point 5) mainly consist of $\mathrm{Mg}$, Si and $\mathrm{Cu}$. The atomic percentage of precipitates indicate that the white blocks, black blocks, and light-gray small blocky precipitates are mainly $\mathrm{AlFeSi}, \mathrm{Mg}_{2} \mathrm{Si}$, and $\mathrm{Al}_{5} \mathrm{Cu}_{2} \mathrm{Mg}_{8} \mathrm{Si}_{6}$, respectively.

Electron microprobe analysis (EPMA) was used to identify the light-gray rod-like phase [circle in Fig. 5(d)] in segregation zones, as shown in Fig. 6.

As shown in Fig. 6, the rod-like precipitates mainly contain $\mathrm{Fe}$, while the small bulky precipitates mainly contain $\mathrm{Fe}, \mathrm{Cu}$,

Fig. 5: Microstructures of segregation zone 
Table 2: EDS analysis results of segregation zone (at.\%)

\begin{tabular}{cccccc} 
Points & Mg & Si & Fe & Cu & Al \\
\hline 1 & 1.20 & 10.70 & 17.54 & 0.56 & Bal. \\
2 & 3.01 & 10.36 & 17.91 & 0.78 & Bal. \\
3 & 55.22 & 25.48 & 1.10 & 0.96 & Bal. \\
4 & 37.89 & 13.70 & 0.85 & 1.23 & Bal. \\
5 & 17.19 & 13.29 & 0.59 & 4.03 & Bal. \\
\hline
\end{tabular}
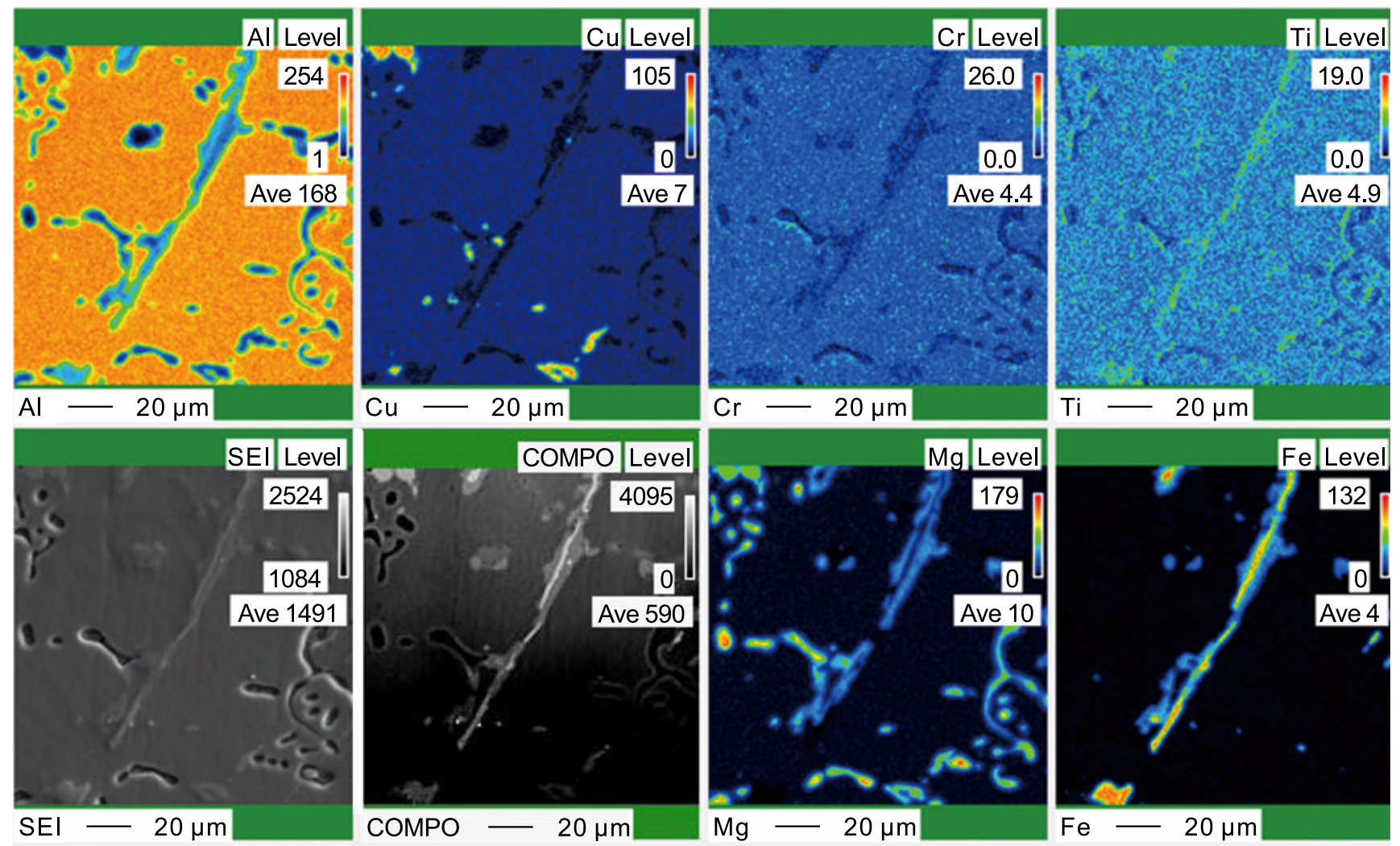

$\mathrm{Mg}$ and Si. The results of XRD and EDS imply that the rodlike precipitates are $\mathrm{AlFeSi}$, and the bulky phases distributed around them are mainly $\mathrm{Al}_{5} \mathrm{Cu}_{2} \mathrm{Mg}_{8} \mathrm{Si}_{6}$.

The above analysis shows that the precipitation phase in the segregation zone of 6061 aluminum alloy wheels is relatively complex and composed of $\mathrm{Al}_{5} \mathrm{Cu}_{2} \mathrm{Mg}_{8} \mathrm{Si}_{6}$ and $\mathrm{AlFeSi}$, in addition to $\mathrm{Mg}_{2} \mathrm{Si}$.

The white streaks at the grain boundary [Fig. 5(d)] were examined by line scanning test (Fig. 7). The Mg content in the white phase is lower than that in the matrix, while the contents
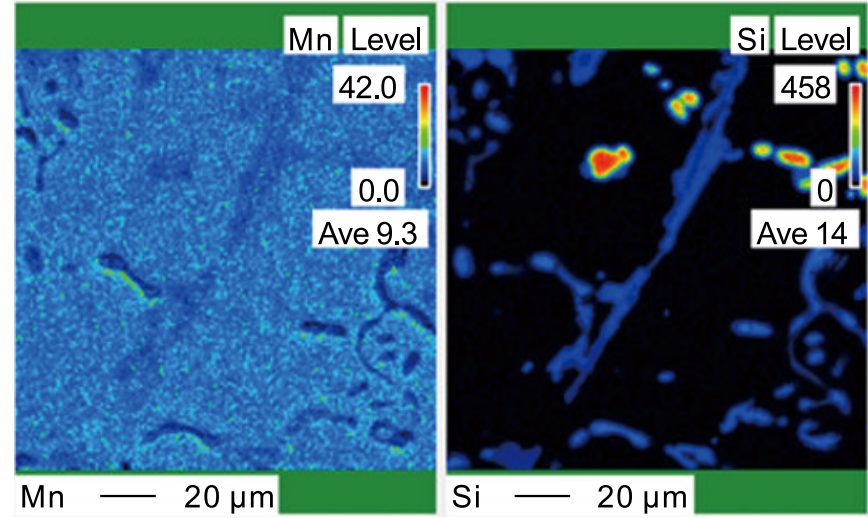

Fig. 6: EPMA image of rod-like phase in segregation zone

of $\mathrm{Fe}$ and $\mathrm{Si}$ are higher than the matrix (Fig. 7). Therefore, it can be determined that the white phase at the grain boundary is also $\mathrm{AlFeSi}$.

The segregation of $\mathrm{Mg}_{2} \mathrm{Si}$ and $\mathrm{Al}_{5} \mathrm{Cu}_{2} \mathrm{Mg}_{8} \mathrm{Si}_{6}$ has been approved by some researchers ${ }^{[12-14]}$, but the formation of AlFeSi phase has aroused great controversy ${ }^{[15-17]}$. The types of the precipitation phase in 6061 alloy based on literature are shown in Table $3^{[18-20]}$.
The precipitation reaction of phases during solidification of 6061 aluminum alloy is very complicated (Table 3 ), and it is difficult to determine which type of AlFeSi phase is formed.

The Gibbs energy of 6061 aluminum alloy was calculated by JmatPro (Fig. 8). The $\alpha$-AlFeSi precipitates at $614{ }^{\circ} \mathrm{C}$, which is an unstable phase (Fig. 8). It changes into $\beta$-AlFeSi when the temperature drops to $584.7^{\circ} \mathrm{C}$. 

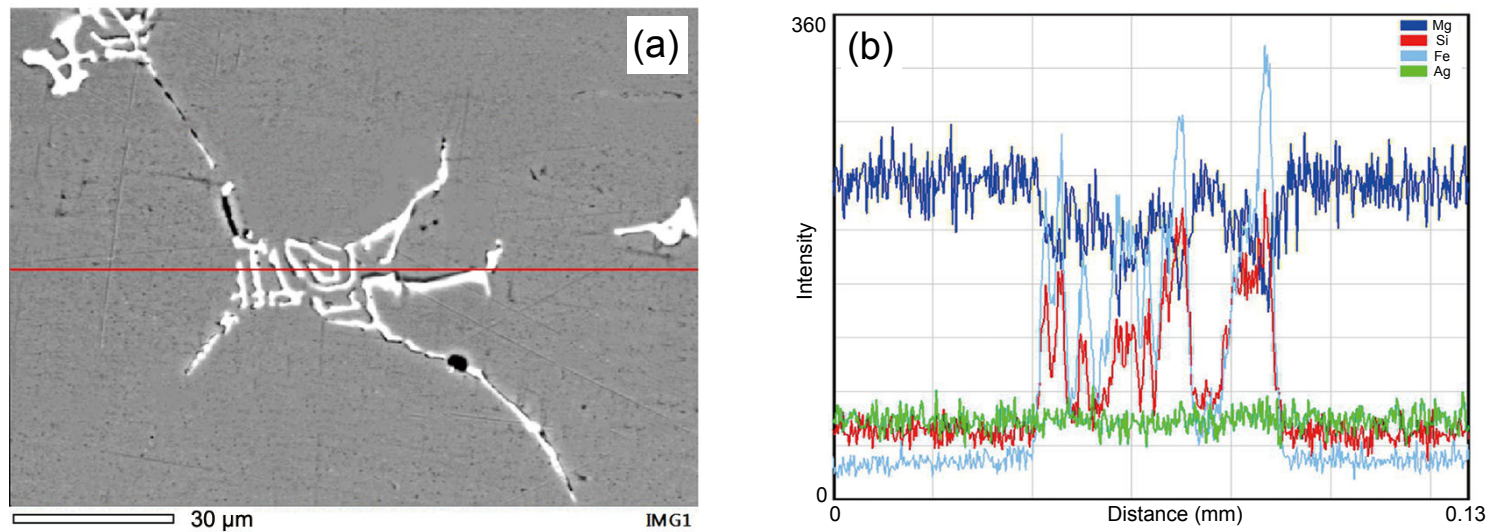

Fig. 7: Distribution of alloy elements in white phase at grain boundary

Table 3: Reactions during solidification of 6061 aluminum alloy

$\begin{array}{cc}\text { Invariant reaction } & \text { Reference } \\ L \rightarrow \mathrm{Al}+\mathrm{Mg}_{2} \mathrm{Si} & {[18]} \\ L \rightarrow \mathrm{Al}_{13} \mathrm{Fe}_{4}+\alpha-\mathrm{Al} & {[19]} \\ L \rightarrow \mathrm{Al}_{13} \mathrm{Fe}_{4} \rightarrow \alpha-\mathrm{AlFeSi}+\alpha-\mathrm{Al} & {[19]} \\ L \rightarrow \alpha-\mathrm{AlFeSi}+\alpha-\mathrm{Al} & {[20]} \\ L+\alpha-\mathrm{AlFeSi} \rightarrow \beta-\mathrm{AlFeS}+\alpha-\mathrm{Al} & {[19]} \\ L \rightarrow \beta-\mathrm{AlFeS}+\alpha-\mathrm{Al} & {[20]} \\ L \rightarrow \beta-\mathrm{AlFeS}+\alpha-\mathrm{Al}+\mathrm{Si} & {[20]} \\ L \rightarrow \beta-\mathrm{AlFeS}+\mathrm{Mg}_{2} \mathrm{Si}+\alpha-\mathrm{Al} & {[19]}\end{array}$

The volume percentages of solid and liquid during solidification of 6061 aluminum alloy were also calculated by JmatPro (Fig. 9).

The 6061 aluminum alloy begins to solidify at $655^{\circ} \mathrm{C}$, and when the temperature drops to $528{ }^{\circ} \mathrm{C}$, it is completely converted into solid phase (Fig. 9), which means the end of solidification, indicating the temperature range of the mushy zone of 6061 aluminum is $528-655^{\circ} \mathrm{C}$.

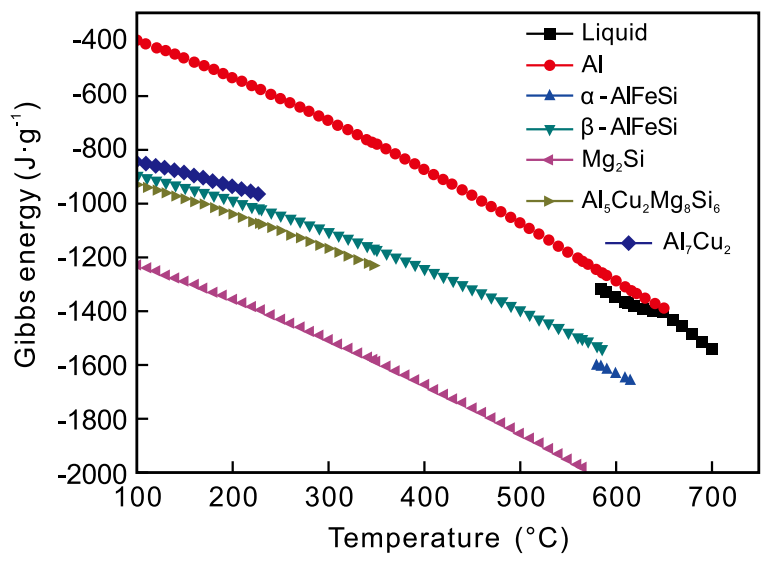

Fig. 8: Gibbs energies of different phases in 6061 aluminum alloy

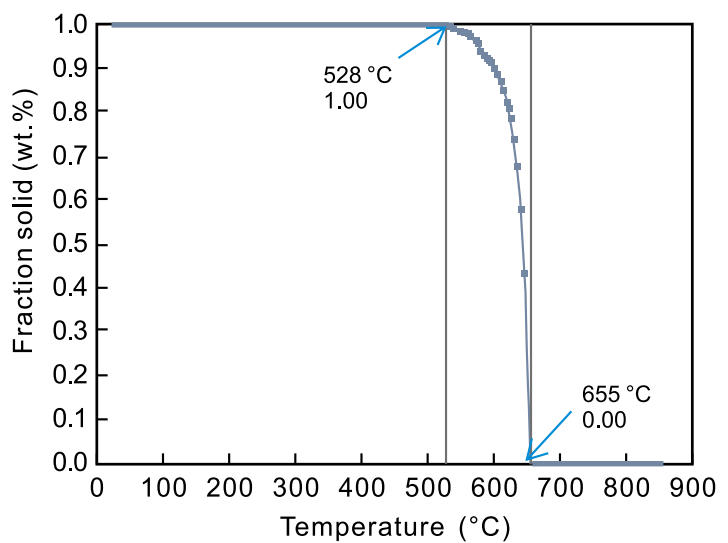

Fig. 9: Solid volume percentage of 6061 aluminum alloy at different temperatures

Based on the above results, the precipitation sequence of 6061 aluminum alloy can be determined as follows:

$$
\begin{gathered}
L \rightarrow \alpha(\mathrm{Al}) \\
L \rightarrow \alpha(\mathrm{Al})+\alpha-\mathrm{AlFeSi} \\
L+\alpha-\mathrm{AlFeSi} \rightarrow \alpha(\mathrm{Al})+\beta-\mathrm{AlFeSi}
\end{gathered}
$$

Since $\alpha$-AlFeSi and $\alpha$-Al belong to non-coherent interfaces, $\mathrm{Mg}_{2} \mathrm{Si}$ phase can easily nucleate and grow at their interface ${ }^{[21]}$, and the reaction formula is:

$$
L \rightarrow \alpha-\mathrm{Al}+\mathrm{Mg}_{2} \mathrm{Si}
$$

With the decrease of temperature, $Q-\mathrm{Al}_{5} \mathrm{Cu}_{2} \mathrm{Mg}_{8} \mathrm{Si}_{6}$ precipitated from $\alpha-\mathrm{Al}^{[22]}$.

Seo et al ${ }^{[8]}$ calculated the diffusion coefficients of different elements in the 6061 aluminum alloy at 1,073 $\mathrm{K}$, and the results are shown in Table 4 , where $D_{0}$ is constant, $Q$ is activation energy, $D$ is diffusion coefficient.

The diffusion coefficient of $\mathrm{Mg}$ is the largest, and those of $\mathrm{Si}$ and $\mathrm{Fe}$ are similar and small (Table 4). This result indicates that the diffusion rates of $\mathrm{Si}$ and $\mathrm{Fe}$ are slower at 1,073 $\mathrm{K}$, while those of $\mathrm{Mg}, \mathrm{Cu}, \mathrm{Cr}$ and $\mathrm{Mn}$ are faster. Therefore, it is not normal to form abundant AlFeSi phase in the R-joint of wheel, which should be related to the cooling conditions. To explore its mechanism, the mold temperature was measured after the wheel was taken out (Fig. 10). 
Table 4: Diffusion coefficients of different elements in 6061 alloy at $1,073 \mathrm{~K}^{[8]}$

$\begin{array}{cccc}\text { Element } & \boldsymbol{D}_{0}\left(\mathrm{~m}^{2} \cdot \mathrm{s}^{-1}\right) & \boldsymbol{Q}\left(\mathrm{kJ} \cdot \mathrm{mol}^{-1}\right) & \boldsymbol{D}\left(\mathrm{m}^{2} \cdot \mathrm{s}^{-1}\right) \\ \mathrm{Mg} & 9.90 \times 10^{-5} & 71.6 & 3.24 \times 10^{-8} \\ \mathrm{Si} & 1.34 \times 10^{-7} & 30 & 4.64 \times 10^{-9} \\ \mathrm{Cu} & 1.06 \times 10^{-7} & 24 & 7.19 \times 10^{-9} \\ \mathrm{Fe} & 2.34 \times 10^{-7} & 35 & 4.63 \times 10^{-9} \\ \mathrm{Cr} & 2.53 \times 10^{-7} & 32.8 & 6.40 \times 10^{-9} \\ \mathrm{Mn} & 1.93 \times 10^{-7} & 31 & 5.98 \times 10^{-9}\end{array}$
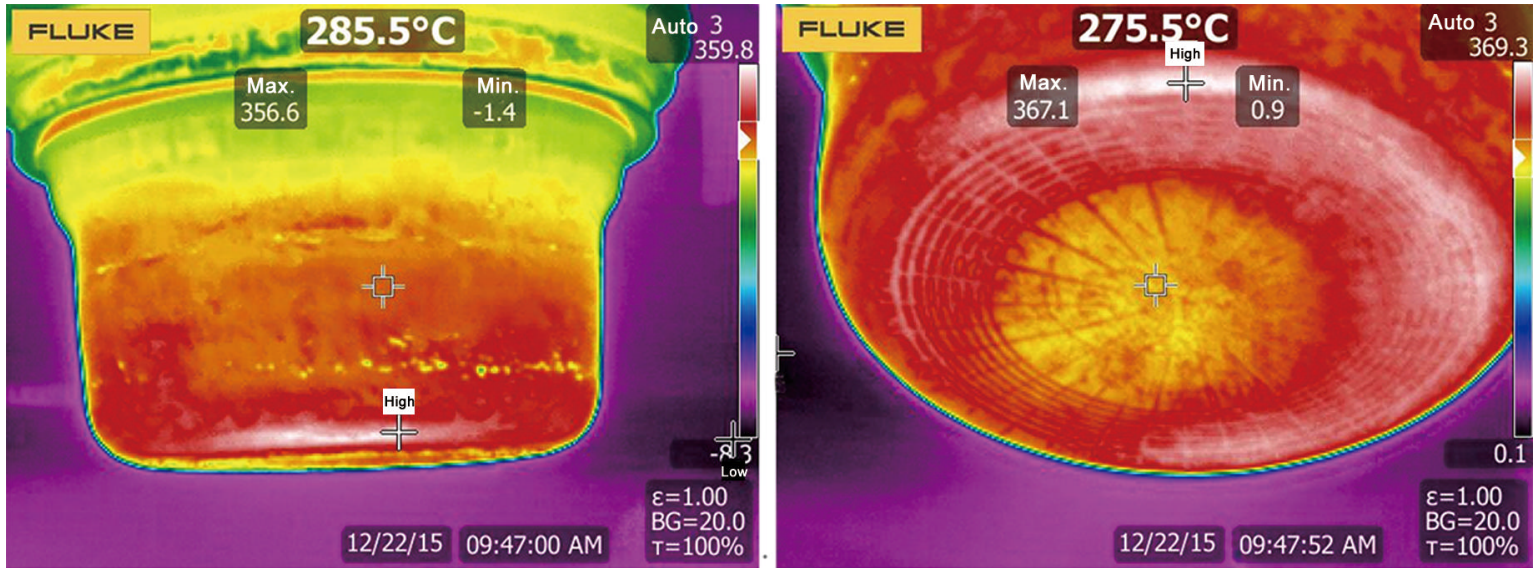

Fig. 10: Temperature map of mold after the wheel being taken out

It can be seen that when the alloy was solidified and the wheel was taken out, the temperature distribution of the mold was uneven. The mold temperature corresponding to the R-joint of the wheel was the highest (Fig. 10), indicating the heat dissipation of the alloy at the R-joint of wheel is the slowest during solidification. Therefore, the mushy zone is maintained for the longest time at this area, providing sufficient time for AlFeSi to grow up, which causes the coarsening of AlFeSi phase.

Figure 11 shows the sectional schematic diagram of the wheel die. It can be seen that the thickness at the R-joint is the greatest, so the heat dissipation at this position is the slowest during solidification (Fig. 11). Therefore, local cooling should be enhanced to avoid the growth of segregation phase such as $\mathrm{AlFeSi}$.

\section{Conclusions}

The 6061 aluminum alloy wheel spokes were prepared by squeeze casting using a metal mold, and the formation mechanism of segregation was studied. The following conclusions can be obtained:

(1) During the solidification of 6061 aluminum alloy, $\mathrm{Mg}_{2} \mathrm{Si}$ and $\alpha$-AlFeSi phases precipitate at first in the mushy zone. With the decrease of temperature, $\alpha$-AlFeSi transforms into $\beta$-AlFeSi and $\mathrm{Al}_{5} \mathrm{Cu}_{2} \mathrm{Mg}_{8} \mathrm{Si}_{6}$ precipitates in the solid phase after the alloy solidification.

(2) The long strip shape segregation occurs in the R-joint, the largest thickness position of 6061 aluminum alloy wheel prepared by squeeze casting.

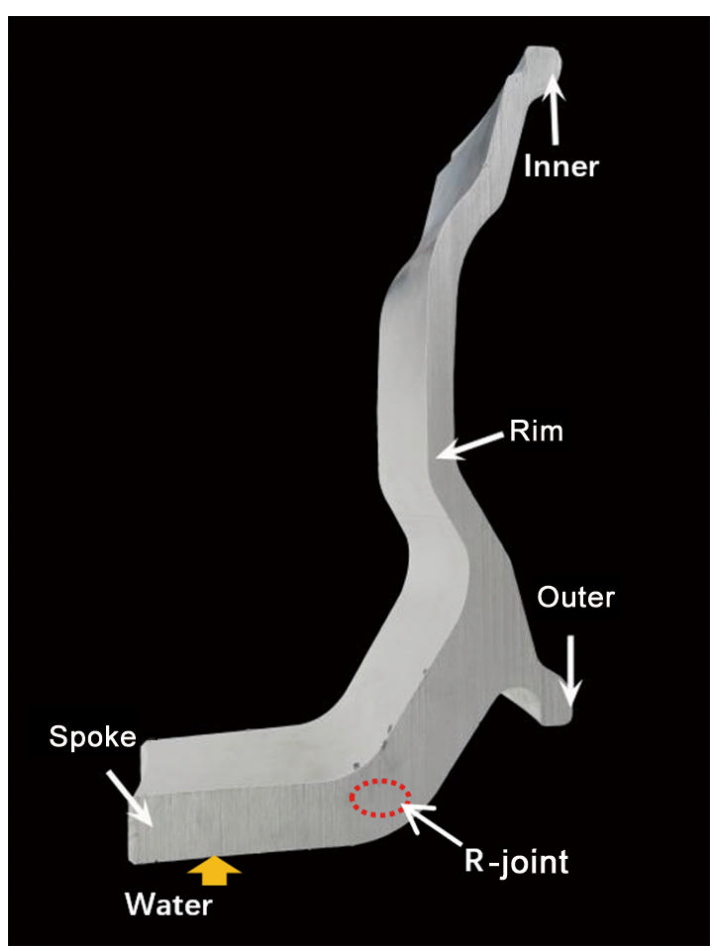

Fig. 11: Sectional chematic diagram of wheel mold 
(3) The segregation zone at R-joint of 6061 aluminum alloy wheel spokes is mainly composed of $\mathrm{Mg}_{2} \mathrm{Si}, \beta-\mathrm{AlFeSi}$ and $\mathrm{Al}_{5} \mathrm{Cu}_{2} \mathrm{Mg}_{8} \mathrm{Si}_{6}$ phases. This segregation is mainly caused by the insufficient cooling, so, cooling should be enhanced at this location to avoid segregation.

\section{Acknowledgement}

This work was financially supported by the National Natural Science Foundation of China (Grant No. 51875365).

\section{References}

[1] Manes A, Peroni L, Scapin M, et al. Analysis of strain rate behavior of an Al 6061 T6 alloy. Procedia Engineering, 2011, 10: 3477-3482.

[2] Viveros K C, Ambriz R R, Amrouche A, et al. Cold hole expansion effect on the fatigue crack growth in welds of a 6061-T6 aluminum alloy. Journal of Materials Processing Technology, 2014, 214(11): 2606-2616.

[3] Nageswara R P, Singh D, Brokmeier H G, et al. Effect of ageing on tensile behavior of ultrafine grained Al 6061 alloy. Materials Science \& Engineering A, 2015, 641: 391-401.

[4] Tocci M, Pola A, La Vecchia G M, et al. Characterization of a new aluminum alloy for the production of wheels by hybrid aluminum forging. Procedia Engineering, 2015, 109: 303-311.

[5] Trifinov V G, Khalikova G R. Liquid forging processing of automobile wheels. Letters on Materials, 2013, 3: 56-59.

[6] Yin F, Wang G X, Hong S Z, et al. Technological study of liquid die forging for the aluminum alloy connecting rod of an air compressor. Journal of Materials Processing Technology, 2003, 139: 462-464.

[7] Stangeland A, Asbjørn M. Thermal strain in the mushy zone for aluminum alloys. Metallurgical and Materials Transactions A, 2006, 37(7): 2219-2229.

[8] Seo H, Gu J H, Park K, et al. Solidification and segregation behaviors in 6061 aluminum alloy. Metals and Materials International, 2013,19(3): 433-438.

[9] Wang $H Q$, Sun $W$ L, Xing $Y Q$. Microstructure Analysis on 6061 Aluminum Alloy after Casting and Diffuses Annealing Process. Physics Procedia, 2013, 50: 68-75.
[10] Magnus S R, Knut M, Ida W, et al. The effect of alloying elements on the ductility of Al-Mg-Si alloys. Materials Science \& Engineering A, 2017, 693: 60-72.

[11] Basak C B, Babu N H. Morphological changes and segregation of $\beta$-Al9Fe2Si2 phase: A perspective from better recyclability of cast Al-Si alloys. Materials and Design, 2016, 108: 277-288.

[12] Mulazimoglu A, Zaluska F, Paray J E. Gruzleski. The effect of strontium on the Mg2Si precipitation process in 6201 aluminum alloy. Metallurgical and Materials Transactions A, 1997, 28: 1289-1295.

[13] Linardi E, Haddad R, Lanzani L. Stability Analysis of the Mg2Si Phase in AA 6061 Aluminum Alloy. Procedia Materials Science, 2012, 1: 550-557.

[14] Ida S, Mary A W, Shahrzad E. Modeling homogenization behavior of Al-Si-Cu-Mg aluminum alloy. Materials \& Design, 2017, 128: 241-249.

[15] Lui A, Grant P S, Stone I C, et al. The Role of Grain Refiner in the Nucleation of AIFeSi Intermetallic Phases During Solidification of a $6 x x x$ Aluminum Alloy. Metallurgical and Materials Transactions A, 2019, 23: 1230-1245.

[16] Turmezey T. AlFe and AlFeSi Intermetallic Phases in Aluminium Alloys. Materials Science Forum, 1987, 13: 121-132.

[17] Osada Y. Distribution of $\alpha$-AIFeSi and $\beta$-AlFeSi particles in surface layer of AA6063 alloy billets after heat treatment. Journal of Materials Science, 2004, 39: 1227-1231.

[18] Hatch J E. Aluminum Properties and Physical Metallurgy. ASM International, 1993.

[19] Sha G, O'Reilly K A Q, Cantor B, et al. Growth related metastable phase selection in a $6 x x x$ series wrought $A l$ alloy. Materials Science and Engineering: A, 2001, 304-306: 612616.

[20] Sha G, O'Reilly K A Q, Cantor B, et al. Quasi-peritectic solidification reactions in $6 \mathrm{XXX}$ series wrought $\mathrm{Al}$ alloys. Acta Materials, 2003, 51: 1883-1897.

[21] Per Skjerpe. Intermetallic phases formed during DC-casting of an Al-0.25 Wt Pct Fe-0.13 Wt Pct Si alloy. Metallurgical Transactions A, 1986, 18: 189-200.

[22] Farkoosh A R, Javidani M, Hoseini M, et al. Phase formation in as-solidified and heat-treated $\mathrm{Al}-\mathrm{Si}-\mathrm{Cu}-\mathrm{Mg}-\mathrm{Ni}$ alloys Thermodynamic assessment and experimental investigation for alloy design. Journal of Alloys and Compounds, 2013, 551: 596-606. 